\title{
Polymer-derived amorphous silica-based inorganic-organic hybrids having alkoxy groups: intermediates for synthesizing microporous amorphous silica materials
}

\author{
Mohd Nazri MOHD SOKRI, ${ }^{*, *}$ Takahiro ONISHI, ${ }^{*}$ Zineb MOULINE, ${ }^{*}$ \\ Yusuke DAIKO, ${ }^{*, * *}$ Sawao HONDA ${ }^{*, * * *}$ and Yuji IWAMOTO ${ }^{*, * *, \dagger}$ \\ *Department of Frontier Materials, Graduate School of Engineering, Nagoya Institute of Technology, \\ Gokiso-cho, Showa-ku, Nagoya 466-8555, Japan \\ ** Department of Renewable Energy and Advanced Membrane Technology Research Centre, Faculty of Petroleum and Renewable \\ Energy Engineering, Universiti Teknologi Malaysia (UTM), Johor Bahru, 81310, Malaysia \\ ${ }^{* * *}$ CREST, Japan Science and Technology Agency, Gokiso-cho, Showa-ku, Nagoya 466-8555, Japan
}

\begin{abstract}
Alkoxy group-functionalized amorphous silica-based inorganic-organic hybrid materials were designed through polymer precursor route, in order to develop a novel route for the fabrication of microporous amorphous silica-based materials. Commercial perhydropolysilazane (PHPS) was chemically modified with alcohols $\left(\mathrm{R}-\mathrm{OH}, \mathrm{R}=\mathrm{n}-\mathrm{C}_{5} \mathrm{H}_{11} \mathrm{OH}, \mathrm{n}-\mathrm{C}_{10} \mathrm{H}_{21} \mathrm{OH}\right)$ at a PHPS (Si basis) to ROH molar ratio of $4 / 1$, and subsequently oxidized to afford alkoxy group-functionalized amorphous silica by exposure to aqueous ammonia vapours at room temperature. Then, the oxidized materials were heat-treated at $600^{\circ} \mathrm{C}$ in air. Nitrogen sorption analysis revealed that micropore volume of the amorphous silica increased upon alkoxy group-functionalization prior to the heat treatment. As a result, higher micropore volume of $0.204 \mathrm{~cm}^{3} / \mathrm{g}$ was achieved, with a specific surface area of $387 \mathrm{~m}^{2} / \mathrm{g}$ for the PHPS-derived amorphous silica chemically modified with $n-\mathrm{C}_{10} \mathrm{H}_{21} \mathrm{OH}$ at the $\mathrm{Si} / \mathrm{n}-\mathrm{C}_{10} \mathrm{H}_{21} \mathrm{OH}$ molar ratio of $2 / 1$. The micropores evaluated by the $\mathrm{SF}$ method were in the size range of $0.43 \mathrm{to} 1.6 \mathrm{~nm}$, and the resulting micropore size distribution plot exhibited a peak at $0.43 \mathrm{~nm}$. The in-situ formation of the microporosity was further studied by the simultaneous thermogravimetry-mass spectrometry analysis. The relationship between the number of carbon atoms in the alkoxy group, the evolution of gaseous species during the heat treatment and the resulting microporosity is discussed.
\end{abstract}

(C2015 The Ceramic Society of Japan. All rights reserved.

Key-words: Perhydropolysilazane, Inorganic-organic silica-based hybrids, Amorphous silica, Microporosity, Thermogravimetrymass spectrometry, Polymer-derived ceramics

[Received April 16, 2015; Accepted June 1, 2015]

\section{Introduction}

The use of chemical approaches in ceramic processing allowed a direct access to numerous types of ceramic materials that can be synthesized and characterized for a broad range of applications. The organometallic precursor route has received growing attention as an attractive ceramic processing method since it has inherent advantages over conventional powder processing methods such as purity control, compositional homogeneity in the ceramic final-product and lower processing temperatures in ceramic preparation. ${ }^{1-3)}$ Moreover, this route provides alternatives towards the synthesis of advanced silicon-based non-oxide ceramics such as silicon nitride $\left(\mathrm{Si}_{3} \mathrm{~N}_{4}\right)$-based ceramics, particularly starting from polysilazanes as reported in several studies. ${ }^{4)-6)}$ Perhydropolysilazane (PHPS) has been extensively studied as a carbon free polymer precursor, that is readily oxidized to yield pure silica with a high ceramic yield, either by pyrolysis in air, ${ }^{7)}$ or by exposure to aqueous ammonia vapour at room temperature. ${ }^{8), 9)}$

To date, micro- and meso-porous structures formation has been often discussed for the polymer-derived amorphous ceramics such as silicon nitride $(\mathrm{Si}-\mathrm{N}),{ }^{10), 11)}$ silicon carbide $(\mathrm{Si}-$

Corresponding author: Y. Iwamoto; E-mail: iwamoto.yuji@nitech. ac.jp

* Preface for this article: Dol http://dx.doi.org/10.2109/jcersj2.123.P9-1
C) ${ }^{12)-17)}$ silicon carbonitride $(\mathrm{Si}-\mathrm{C}-\mathrm{N}),{ }^{18)}$ quaternary $\mathrm{Si}-\mathrm{M}-\mathrm{C}-\mathrm{N}$ $\left(\mathrm{M}=\mathrm{B},{ }^{19), 20)} \mathrm{Ni}^{21)}\right)$, silicon oxycarbide $(\mathrm{SiOC}),{ }^{22)-24)}$ and silica (Si-O). ${ }^{7), 25), 26)}$ During the crosslinking and subsequent hightemperature pyrolysis of polymer precursors, by-product gases such as $\mathrm{CH}_{4}, \mathrm{NH}_{3}$ and $\mathrm{H}_{2}$ were detected, ${ }^{5,27)}$ and the microporosity in the polymer-derived non-oxide amorphous ceramics could be assigned to the release of the small gaseous species formed in-situ. ${ }^{11), 27)}$

Recently, Iwamoto et al. ${ }^{7)}$ reported an approach in controlling the micro- and meso-porous structure formation using organosubstituted polysilazane precursor, in which the organic moieties acted as a "sacrificial template" during polymer to ceramic conversion by heat treatment in air, thus allowing the micro- and meso-porous structure formation. In our recent study, alkoxy group-functionalized PHPSs ${ }^{28)}$ were synthesized using a variety of alcohols, and successfully converted to microporous amorphous silica by oxidative crosslinking at $270^{\circ} \mathrm{C}$ followed by pyrolysis at $600^{\circ} \mathrm{C}$ in air (Route I in Fig. 1). ${ }^{26)}$ However, due to the vigorous oxidation reaction of PHPSs, it was difficult to investigate the relationship between their pyrolytic behaviours and the microporous structure formation.

Herein, as continuation of our ongoing studies, alkoxy groupfunctionalized amorphous silica-based inorganic-organic hybrid materials were designed using room temperature oxidation technique. ${ }^{8)}$ Then, the thermal conversion of the hybrids to micro- 


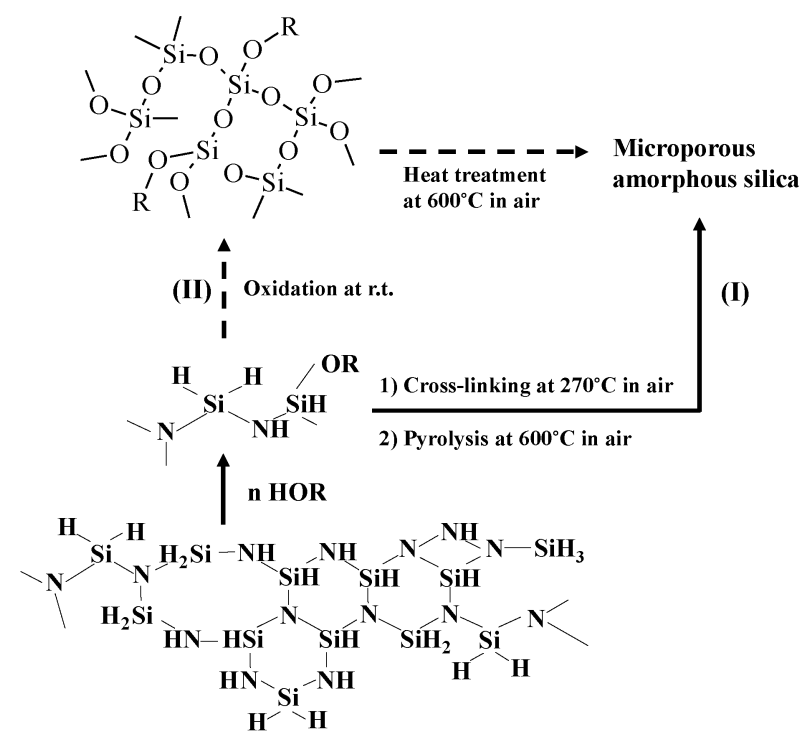

Perhydropolysilazane (PHPS)

Fig. 1. Synthesis of microporous amorphous silica from alkoxy-group functionalized PHPS. Route I: Two-step heat treatment. ${ }^{26)}$ Route II: Oxidation step followed by heat treatment of the alkoxy-group functionalized amorphous silica intermediate.

porous amorphous silica was investigated by the simultaneous thermogravimetry-mass spectrometry (TG-MS) analysis (Route II in Fig. 1). The relationship between the number of carbon atoms in the alkoxy group, the gaseous species formed in-situ during the thermal treatment and the microporosity within the final silica materials is discussed and compared with our previous results, ${ }^{26)}$ in order to achieve a better understanding of the microporous structure formation in polymer-derived amorphous silica.

\section{Experimental procedures}

\subsection{Precursor synthesis}

Commercially available perhydropolysilazane (PHPS, Type NN110, 20\% xylene solution, AZ Electronic Materials, Japan) was used as a starting polymer. For the chemical modification of PHPS, n-pentanol $\left(n-\mathrm{C}_{5} \mathrm{H}_{11} \mathrm{OH}\right)$ and n-decanol $\left(\mathrm{n}-\mathrm{C}_{10} \mathrm{H}_{21} \mathrm{OH}\right)$ were used. The reaction between as-received PHPS and the alcohols was carried out under dry argon (Ar) atmosphere using Schlenk techniques. ${ }^{29)}$ PHPS (Si basis)/ROH molar ratio of $4 / 1$ was applied for both samples, and the molar ratio of 2/1 was further investigated for the PHPS chemically modified with $n-\mathrm{C}_{10} \mathrm{H}_{21} \mathrm{OH}$. In a typical procedure, the alcohol was added dropwise to a xylene solution of as-received PHPS with magnetic stirring at room temperature, followed by the addition of toluene to decrease the PHPS concentration from 20 to $1 \mathrm{wt} \%$. After the addition was completed, the mixture was refluxed for $1 \mathrm{~h}$ under Ar flow and cooled down to room temperature. The xylene and toluene were removed from the reaction mixture under vacuum to give the alcohol adduct as a viscous liquid.

\subsection{Conversion of the polymer precursor to amor- phous silica-based hybrid and pyrolysis}

The oxidative polymer/amorphous silica-based hybrid conversion was carried out by exposing the polymer precursor to vapour from aqueous ammonia $\left(\mathrm{NH}_{3}\right)$ according to the procedure reported by Kubo et al. ${ }^{8)}$ In this process, $15 \mathrm{~mL}$ of aqueous $\mathrm{NH}_{3}$ was placed in a $200 \mathrm{~mL}$ beaker with a slightly open lid and the polymer precursor (ca. $600 \mathrm{mg}$ ) was suspended over the aqueous $\mathrm{NH}_{3}$ until the silica-based hybrid formed as white powder. The resulting amorphous silica-based hybrid was ground to a fine powder using a mortar and pestle, then heat-treated in a furnace under air flow up to $600^{\circ} \mathrm{C}$ for a period of time of $6 \mathrm{~h}$. Then the temperature was maintained at $600^{\circ} \mathrm{C}$ for an additional hour, and finally cooled down to room temperature to afford amorphous silica as white powders.

\subsection{Characterization}

Fourier transform infrared (FT-IR) spectra of the polymers, the polymer-derived amorphous silica-based hybrids and pyrolyzed products were recorded using $\mathrm{KBr}$ pellets over the range of 4000 to $400 \mathrm{~cm}^{-1}$ (FT/IR-4200 IF, Jasco, Japan).

The thermal behaviours up to $1000^{\circ} \mathrm{C}$ were studied by simultaneous thermogravimetric (TG) and mass spectroscopic (MS) analyses (Model TG/DTA6300, Hitachi High Technologies Ltd., Tokyo, Japan/Model JMS-Q1050GC, JEOL, Tokyo, Japan). The measurements were performed under flowing mixed gas of helium $(\mathrm{He})$ and oxygen $\left(\mathrm{O}_{2}\right)\left(\mathrm{He}: \mathrm{O}_{2}=4: 1,100 \mathrm{~mL} / \mathrm{min}\right)$ with a heating rate of $20^{\circ} \mathrm{C} / \mathrm{min}$. To avoid the presence of dominant fragment peaks at around $m / z=32\left(\mathrm{O}_{2}{ }^{+}\right)$related to the presence of $\mathrm{O}_{2}$, the $m / z$ ratios in the range of 20 to 35 were excluded from the MS spectra for all the samples. Conventional TG analyses in air were also performed on the polymer-derived amorphous silica-based hybrids up to $1000^{\circ} \mathrm{C}$ at a heating rate of $100^{\circ} \mathrm{C} / \mathrm{h}$ (Model TG8120, Rigaku, Tokyo, Japan), in order to examine the influence of the $\mathrm{He}$ and $\mathrm{O}_{2}$ mixed gas atmosphere.

The pore size distribution for the pyrolyzed samples was determined using $\mathrm{N}_{2}$ sorption technique with the $\mathrm{N}_{2}$ relative pressures ranging from 0 to 0.99 (Model Belsorp Max, BEL Japan Inc., Osaka, Japan). The micropores $\left(r_{\text {pore }}<2.0 \mathrm{~nm}\right)$ and mesopores $\left(2.0 \mathrm{~nm} \leqq r_{\text {pore }}<50 \mathrm{~nm}\right)$ of the polymer-derived amorphous silica materials were characterized by the $\mathrm{SF}^{30}$ and $\mathrm{BJH}^{31)}$ methods, respectively.

\section{Results and discussion}

\subsection{Chemical structures identified by FT-IR spec- troscopic analysis}

The chemical structures of the polymeric precursors were assessed based on their FT-IR spectra. As shown in Fig. 2(a), asreceived PHPS exhibited absorption bands at $3400 \mathrm{~cm}^{-1}(\nu \mathrm{N}-\mathrm{H})$, $2150 \mathrm{~cm}^{-1}(\nu \mathrm{Si}-\mathrm{H}), 1180 \mathrm{~cm}^{-1}(\delta \mathrm{N}-\mathrm{H})$ and $840-1020 \mathrm{~cm}^{-1}(\delta \mathrm{Si}-$ $\mathrm{N}-\mathrm{Si}){ }^{4), 26), 32)}$ The spectra of the PHPS modified with $\mathrm{n}-\mathrm{C}_{5} \mathrm{H}_{11} \mathrm{OH}$ [Fig. 2(b)] and that with $n-\mathrm{C}_{10} \mathrm{H}_{21} \mathrm{OH}$ [Fig. 2(c)] showed additional absorption bands at $2950-2850 \mathrm{~cm}^{-1}(\nu \mathrm{C}-\mathrm{H}), 1450 \mathrm{~cm}^{-1}$ $\left(\delta \mathrm{CH}_{3}\right)$, and $1090 \mathrm{~cm}^{-1}(\nu \mathrm{Si}-\mathrm{OR}){ }^{26), 32)}$ The intensity of the $\mathrm{C}-\mathrm{H}$ absorption band remarkably increased with increasing number of carbon atom in the alcohol used for the chemical modification. By increasing $\mathrm{Si} / \mathrm{n}-\mathrm{C}_{10} \mathrm{H}_{21} \mathrm{OH}$ molar ratio from $4 / 1$ to $2 / 1$ [Fig. 2(d)], the $\mathrm{Si}-\mathrm{H}$ absorption band intensity at $2150 \mathrm{~cm}^{-1}$ decreased remarkably while that at $1090 \mathrm{~cm}^{-1}$ assigned to $\mathrm{Si}-$ $\mathrm{OR}$ increased. However, a new broad absorption band assigned to $\nu \mathrm{O}-\mathrm{H}^{33)}$ appeared at around $3400 \mathrm{~cm}^{-1}$ thus overlapping the $\mathrm{N}-\mathrm{H}$ band, which suggests the existence of unreacted $n-\mathrm{C}_{10} \mathrm{H}_{21} \mathrm{OH}$.

After exposure to vapours from aqueous $\mathrm{NH}_{3}$, the absorption bands corresponding to the as-received PHPS completely disappeared, and new absorption bands appeared at $3400(\mathrm{Si}-\mathrm{OH})^{33)}$ and $1090 \mathrm{~cm}^{-1}(\mathrm{Si}-\mathrm{O}-\mathrm{Si})^{33)}$ [Fig. 2(a)]. In addition to these absorption bands, the spectra of the chemically modified PHPSs exhibited C-H absorption bands in the vicinity of 2950 to 2850 $\mathrm{cm}^{-1}$ [Figs. 2(b)-2(d)]. These results indicate that the chemically 


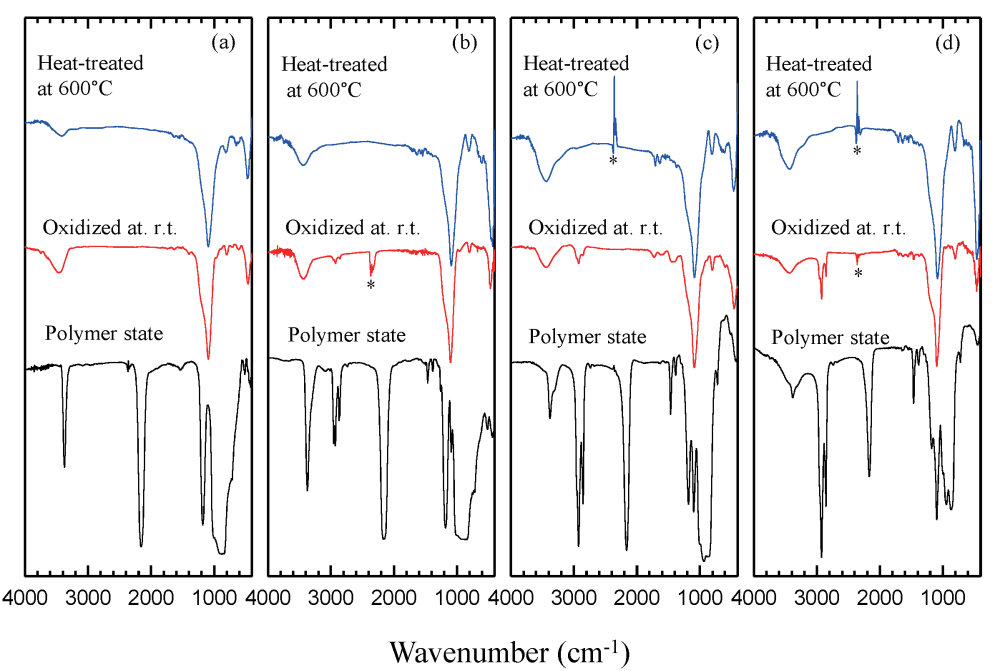

Fig. 2. FT-IR spectra of samples in the polymer state, after oxidation at r.t. (exposure to aqueous $\mathrm{NH}_{3}$ vapours), and the final product after heat treatment at $600^{\circ} \mathrm{C}$ in air. Legend: (a) as-received PHPS, (b) $\mathrm{C}_{5} \mathrm{H}_{11} \mathrm{O}$ group-functionalized PHPS at Si/n$\mathrm{C}_{5} \mathrm{H}_{11} \mathrm{OH}$ molar ratio of 4/1, (c) $\mathrm{C}_{10} \mathrm{H}_{21} \mathrm{O}$ group-functionalized PHPS at $\mathrm{Si} / \mathrm{n}-\mathrm{C}_{10} \mathrm{H}_{21} \mathrm{OH}$ molar ratio of 4/1, and (d) $2 / 1$ ( ${ }^{*}$ indicating background, absorption due to $\mathrm{CO}_{2}$ ).

modified PHPSs were oxidized and successfully converted to alkoxy group-functionalized amorphous silica.

The polymer derived amorphous silica-based hybrids were further heat-treated at $600^{\circ} \mathrm{C}$ in air. As shown in Figs. 2(b)-2(d), the $\mathrm{C}-\mathrm{H}$ absorption bands completely disappeared, and the spectra for these samples were similar to that of the $600^{\circ} \mathrm{C}$ heat-treated amorphous silica derived from as-received PHPS [Fig. 2(a)].

\subsection{Microporosity of polymer-derived amorphous silica}

The textural properties of the heat-treated samples at $600^{\circ} \mathrm{C}$ were studied by $\mathrm{N}_{2}$ physisorption at $-196^{\circ} \mathrm{C}(77 \mathrm{~K})$. The PHPSderived amorphous silica generated a non-porous type III isotherm according to the IUPAC classification method [Fig. 3(a)]. The isotherm of $\mathrm{n}-\mathrm{C}_{5} \mathrm{H}_{11} \mathrm{O}$-modified amorphous silica exhibited a transitional type between type I and type IV without hysteresis loops. The $\mathrm{N}_{2}$ uptake at the relative pressure lower than $\mathrm{P} / \mathrm{P}_{\mathrm{o}}=$ 0.2 is related to the micropore filling, while another slight up take above $\mathrm{P} / \mathrm{P}_{\mathrm{o}}=0.9$ is thought to be related to the meso- and/or macroporosity generated by agglomeration of the powdered sample. Thus, the isotherm of this sample is ascribed to type I-related microporous material [Fig. 3(b)]. The isotherm of n$\mathrm{C}_{10} \mathrm{H}_{21} \mathrm{O}$-modified amorphous silica also presented a similar transitional type. The $\mathrm{N}_{2}$ uptake below $\mathrm{P} / \mathrm{P}_{\mathrm{o}}=0.2$ remarkably increased with increasing the carbon number in the alkoxy group from 5 to 10 [Fig. 3(c)], and further increase in the $\mathrm{N}_{2}$ uptake was achieved by increasing the $\mathrm{Si} / \mathrm{ROH}$ ratio from $4 / 1$ to $2 / 1$ [Fig. 3(d)].

Figure 4(a) shows the pore size distribution (PSD) plots obtained for the heat-treated samples at $600^{\circ} \mathrm{C}$. The micropore volumes for these samples are plotted as a function of number of carbon atoms in the alkoxy group as shown in Fig. 4(b). Compared with the non-porous amorphous silica, an apparent enhancement in the micropore volume was achieved by the alkoxy group-functionalization prior to the heat treatment. The micropores evaluated for the sample derived from $n-C_{5} \mathrm{H}_{11} \mathrm{O}$ group-functionalized silica were in a range of 0.43 to $1.0 \mathrm{~nm}$ in size. The resulting PSD plot exhibited a peak at $0.5 \mathrm{~nm}$, and the micropore volume was measured to be $0.024 \mathrm{~cm}^{3} / \mathrm{g}$. Upon

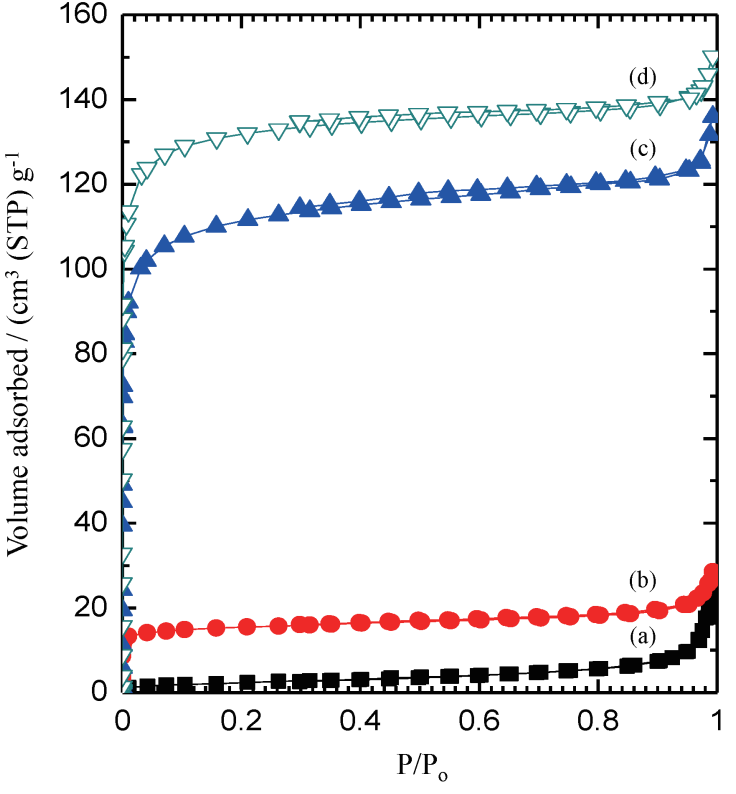

Fig. 3. Nitrogen sorption isotherms for samples after heat treatment at $600^{\circ} \mathrm{C}$ in air. Legend: (a) PHPS-derived amorphous silica. (b) $\mathrm{C}_{5} \mathrm{H}_{11} \mathrm{O}$ group-functionalized PHPS-derived amorphous silica at $\mathrm{Si} / \mathrm{n}-\mathrm{C}_{5} \mathrm{H}_{11} \mathrm{OH}$ molar ratio of $4 / 1$, (c) $\mathrm{C}_{10} \mathrm{H}_{21} \mathrm{O}$ group-functionalized PHPS-derived amorphous silica at $\mathrm{Si} / \mathrm{n}-\mathrm{C}_{10} \mathrm{H}_{21} \mathrm{OH}$ molar ratio of 4/1, and (d) $2 / 1$.

functionalization with the long alkoxy group $\left(n-\mathrm{C}_{10} \mathrm{H}_{21} \mathrm{O}\right)$, the PSD plot extended to approximately $1.6 \mathrm{~nm}$ in size, while the PSD was peaked at $0.43 \mathrm{~nm}$, and the micropore volume increased to $0.173 \mathrm{~cm}^{3} / \mathrm{g}$. By increasing the $\mathrm{Si} / \mathrm{n}-\mathrm{C}_{10} \mathrm{H}_{21} \mathrm{OH}$ molar ratio from $4 / 1$ to $2 / 1$, the PSD remained almost unchanged, while the micropore volume and specific surface area reached $0.204 \mathrm{~cm}^{3} / \mathrm{g}$ and $387 \mathrm{~m}^{2} / \mathrm{g}$, respectively.

The adsorption/desorption isotherms and the resulting PSD plots obtained in this study were similar to those obtained for the polymer-derived amorphous silica samples previously synthesized by the two-step heat treatment (Route I in Fig. 1). ${ }^{26)}$ The variations in the micropore volumes were also compatible 


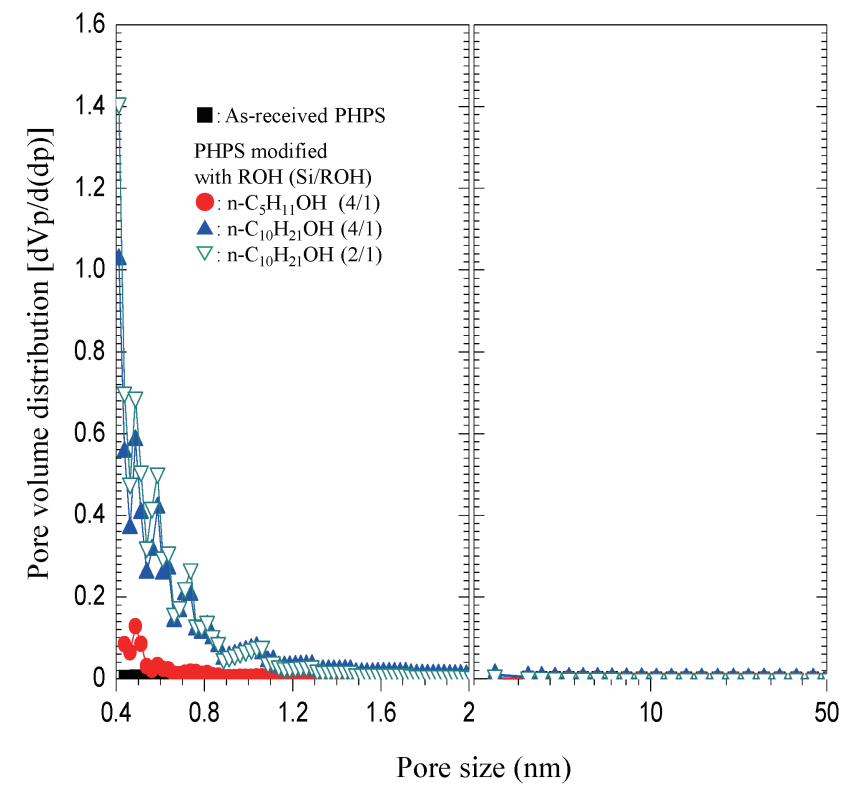

(a)

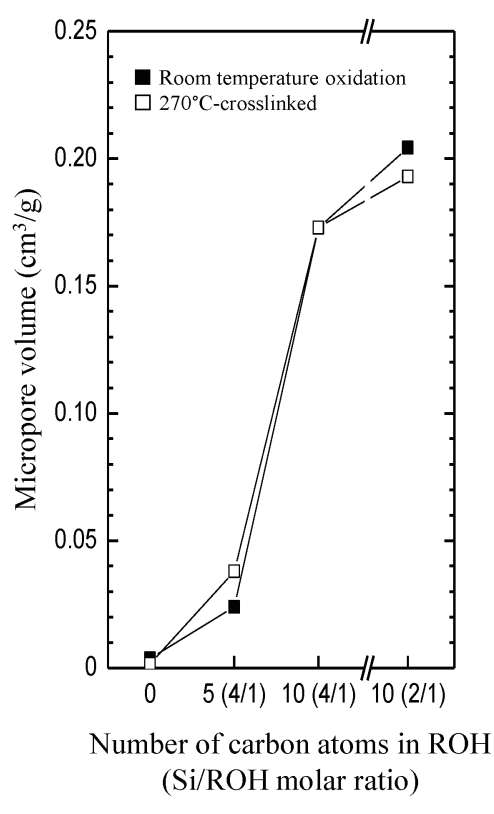

(b)

Fig. 4. Micro- and mesoporous structure of heat-treated samples at $600^{\circ} \mathrm{C}$, evaluated by the nitrogen sorption analysis. (a) Pore size distribution. (b) Micropore volume as a function of number of carbon atoms in ROH. Between brackets are the values of $(\mathrm{Si} / \mathrm{ROH})$ molar ratios used for the chemical modification of PHPS.

with those previously reported for the amorphous silica samples synthesized by the two-step heat treatment [Fig. 4(b)].

\subsection{Results of TG-MS analysis}

To study the pyrolytic behaviours more extensively, TG-MS analysis was performed on the polymer-derived samples after the room temperature oxidation. The results were summarized and shown in Figs. 5-7. The PHPS-derived amorphous silica showed a slight weight loss at 150 up to $400^{\circ} \mathrm{C}$, and exhibited a weight gain of approximately $2 \%$ at 400 up to $750^{\circ} \mathrm{C}$ [Fig. 5(a)]. The MS spectrum measured at $200^{\circ} \mathrm{C}$ is shown in Fig. 5(b). The spectrum composed of $\mathrm{m} / \mathrm{z}$ ratios at 106, 91, 77, 63, 51, and 39 was identical to that reported for xylene. ${ }^{34), 35)}$ Since the molecular ion $(m / z=106)$ and the tropylium ion $(m / z=91)$ were detected at 150 up to $400^{\circ} \mathrm{C}$ [Fig. 5(c)], the observed weight loss is mainly due to the residual xylene, while the slight weight gain may be caused by oxidation reactions occurring at the $\mathrm{Si}-\mathrm{O}-\mathrm{Si}$ amorphous network structural defects, ${ }^{36), 37)}$ as a result of the ambient temperature synthesis applied in this study.

As shown in Fig. 6(a), the silica-based hybrid containing n$\mathrm{C}_{5} \mathrm{H}_{11} \mathrm{O}$ groups exhibited a weight loss of approximately $11 \%$ at 150 up to $700^{\circ} \mathrm{C}$, and the differential thermal analysis (DTA) resulted in the detection of a dominant exothermic peak centered at $320^{\circ} \mathrm{C}$. The MS spectrum measured at $320^{\circ} \mathrm{C}$ is shown in Fig. 6(b). The $\mathrm{m} / \mathrm{z}$ ratios at 57 and 43 were assigned to $\mathrm{C}_{4} \mathrm{H}_{9}{ }^{+}$and $\mathrm{C}_{3} \mathrm{H}_{7}{ }^{+}$, respectively. These fragment ions could result from the $\alpha$ cleavage in the $\mathrm{n}_{-} \mathrm{C}_{5} \mathrm{H}_{11} \mathrm{O}$ group, ${ }^{34), 38)}$ while those at $70\left(\mathrm{C}_{5} \mathrm{H}_{10}{ }^{\circ+}\right)$ and $55\left(\mathrm{C}_{4} \mathrm{H}_{7}{ }^{+}\right)$could be derived from traces of unreacted n$\mathrm{C}_{5} \mathrm{H}_{11} \mathrm{OH}^{34), 39)}$ The smaller species, $m / z$ ratios at 44 and 18 were assigned to $\mathrm{CO}_{2}{ }^{+}$and $\mathrm{H}_{2} \mathrm{O}^{+}$, respectively. By monitoring the fragment ions with $\mathrm{m} / z$ ratios at 57 and 43 , it was confirmed that the decomposition of $n-\mathrm{C}_{5} \mathrm{H}_{11} \mathrm{O}$ group mainly occurred at 250 to $500^{\circ} \mathrm{C}$ [Fig. 6(c)]. Simultaneously, combustion of the in-situ formed hydrocarbons started at around $250^{\circ} \mathrm{C}$, while the evolution of $\mathrm{CO}_{2}$ and $\mathrm{H}_{2} \mathrm{O}$ was detected up to approximately $650^{\circ} \mathrm{C}$ [Fig. 6(d)].
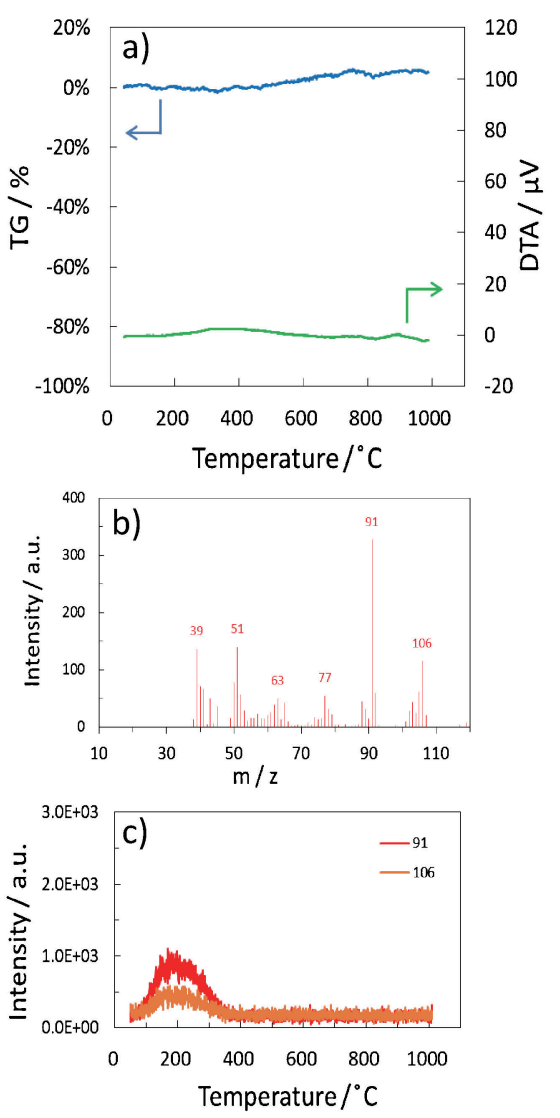

Fig. 5. Thermal behavior of PHPS-derived amorphous silica. a) TGDTA, b) Monitoring of gaseous species by mass spectrometry at $200^{\circ} \mathrm{C}$ and (c) Continuous in-situ monitoring of gaseous species with $\mathrm{m} / \mathrm{z}=106$ and 91 by mass spectrometry. 

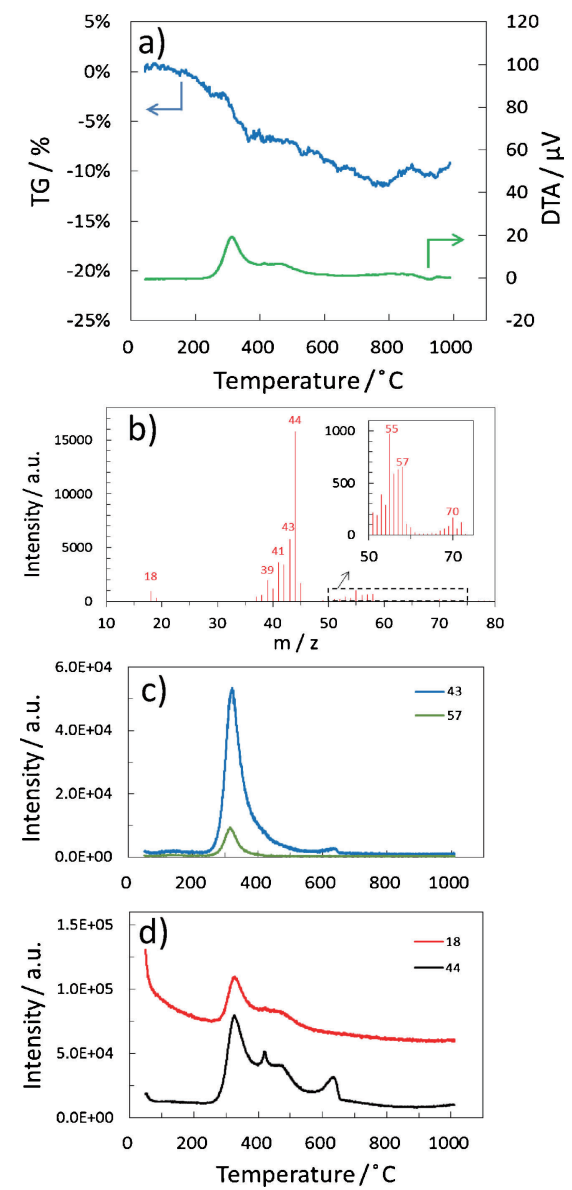

Fig. 6. Thermal behavior of $\mathrm{n}-\mathrm{C}_{5} \mathrm{H}_{11} \mathrm{O}$ group-functionalized amorphous silica. a) TG-DTA, b) Monitoring of gaseous species by mass spectrometry at $200^{\circ} \mathrm{C}$. Continuous in-situ of gaseous species with $\mathrm{m} / \mathrm{z}=$ (c) $57\left(\mathrm{C}_{4} \mathrm{H}_{9}{ }^{+}\right), 43\left(\mathrm{C}_{3} \mathrm{H}_{7}^{+}\right)$, and (d) $44\left(\mathrm{CO}_{2}^{+}\right), 18\left(\mathrm{H}_{2} \mathrm{O}^{+}\right)$by mass spectrometry.

With increasing number of carbon atoms in the alkoxy group from 5 to 10 as well as increasing the $\mathrm{Si} / \mathrm{ROH}$ from $4 / 1$ to $2 / 1$, the weight loss at 150 up to $700^{\circ} \mathrm{C}$ increased to $55 \%$, and the exothermic peak became much more pronounced [Fig. 7(a)]. The MS spectrum measured during the weight loss exhibited sequential peaks 14 mass units apart at $m / z=85,71,57$ and 43 , which can be assigned to the fragment ions derived from hydrocarbons formed in-situ by the typical $\alpha$-cleavage in the $n-\mathrm{C}_{10} \mathrm{H}_{21} \mathrm{O}$ group, followed by the sequential $\mathrm{C}-\mathrm{C}$ bond cleavage which releases methylene units. ${ }^{34), 40)}$ However, the spectrum exhibited other peaks at $m / z=70\left(\mathrm{C}_{5} \mathrm{H}_{10}{ }^{+}\right)$and $55\left(\mathrm{C}_{4} \mathrm{H}_{7}{ }^{+}\right)$assigned as the fragment ions derived from $n-\mathrm{C}_{10} \mathrm{H}_{21} \mathrm{OH}$ [Fig. 7(b)]. ${ }^{34), 41)}$

The thermal decomposition and subsequent combustion behaviours for the $n-\mathrm{C}_{10} \mathrm{H}_{21} \mathrm{O}$ group-functionalized silica were similar to those for the $\mathrm{n}_{-} \mathrm{C}_{5} \mathrm{H}_{11} \mathrm{O}$ group-functionalized sample, while the $\mathrm{CO}_{2}{ }^{+}$ion intensities detected at around $300^{\circ} \mathrm{C}$ were apparently higher than those for the $n-\mathrm{C}_{5} \mathrm{H}_{11} \mathrm{O}$ group-functionalized sample [Figs. 7(c) and 7(d)].

\subsection{Microporosity formations of polymer-derived amorphous silica}

The intrinsic microporosity of the PHPS-derived amorphous silica heat-treated at $600^{\circ} \mathrm{C}$ is thought to be similar to that of the sol gel-derived amorphous silica. As for the disordered form of $\beta$-cristobalite, considered to be the generally accepted structure
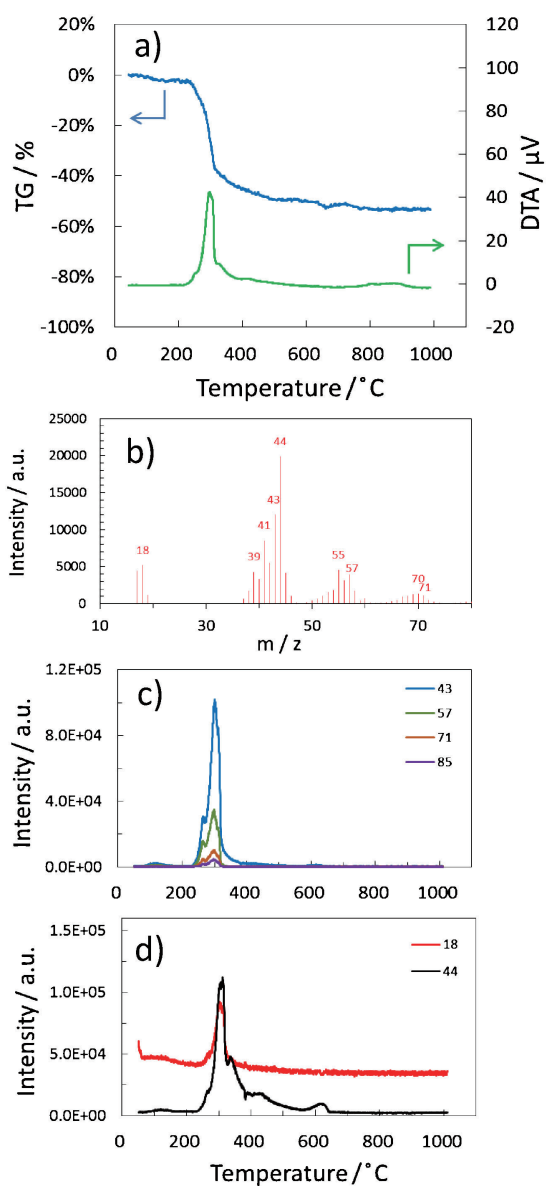

Fig. 7. Thermal behavior of $\mathrm{n}-\mathrm{C}_{10} \mathrm{H}_{21} \mathrm{O}$ group-functionalized amorphous silica $(\mathrm{Si} / \mathrm{ROH}=2 / 1)$. a) TG-DTA, b) Monitoring of gaseous species by mass spectrometry at $200^{\circ} \mathrm{C}$. Continuous in-situ monitoring of gaseous species with $\mathrm{m} / \mathrm{z}=$ (c) $85\left(\mathrm{C}_{6} \mathrm{H}_{13}{ }^{+}\right), 71\left(\mathrm{C}_{5} \mathrm{H}_{11}{ }^{+}\right), 57\left(\mathrm{C}_{4} \mathrm{H}_{9}{ }^{+}\right)$, $43\left(\mathrm{C}_{3} \mathrm{H}_{7}^{+}\right)$and (d) $44\left(\mathrm{CO}_{2}^{+}\right), 18\left(\mathrm{H}_{2} \mathrm{O}^{+}\right)$by mass spectrometry.

of glass, it is composed of 5- and 6-membered $\mathrm{Si}-\mathrm{O}-\mathrm{Si}$ rings with estimated ring size of approximately $0.3 \mathrm{~nm} .{ }^{42), 43)}$ Moreover, it has been suggested that PHPS contains 2-, 3- and 4-membered $\mathrm{Si}-\mathrm{N}-\mathrm{Si}$ ring clusters, as microporous units. ${ }^{5), 27)}$ Upon oxidation at room temperature, the ring clusters are readily converted to $\mathrm{Si}-$ O-Si linkages, which could serve as nucleation sites for subsequent growth of micropores during the heat treatment. However, the diameters of the resulting 5- and 6-membered rings are too small for the $\mathrm{N}_{2}$ probe molecule to access $(0.364 \mathrm{~nm}) .{ }^{44)}$ Consequently, the PHPS-derived amorphous silica was characterized as non-porous.

The weight losses evaluated for amorphous silica-based hybrid containing $n-\mathrm{C}_{5} \mathrm{H}_{11} \mathrm{O}$ group $(\mathrm{Si} / \mathrm{ROH}=4 / 1)$ and $\mathrm{n}-\mathrm{C}_{10} \mathrm{H}_{21} \mathrm{O}$ group $(\mathrm{Si} / \mathrm{ROH}=2 / 1)$ were compatible with those obtained by the conventional TG analysis in air (11 and 57\%, respectively). Thus, the microporous structure formations shown in Fig. 4 can be discussed based on the pyrolytic behaviours shown in Figs. 6 and 7. As mentioned above, the thermal decomposition and subsequent combustion of the alkoxy group led to the in-situ formation of gaseous species, and eventually contributed to the formation of micropores, detected using $\mathrm{N}_{2}$ as a probe molecule. The kinetic diameters of main components of the gaseous species $\mathrm{C}_{4} \mathrm{H}_{9}{ }^{+}\left(\mathrm{n}-\mathrm{C}_{4} \mathrm{H}_{10}\right), \mathrm{C}_{3} \mathrm{H}_{7}{ }^{+}\left(\mathrm{n}-\mathrm{C}_{3} \mathrm{H}_{8}\right)$ and $\mathrm{CO}_{2}$ are in the range of $0.33-0.43 \mathrm{~nm} .{ }^{44)}$ Since the micropore volume increased consistently with the number of carbon atoms in the alkoxy group as 
shown in Fig. 4(b), it is suggested that the micropore volume can be controlled by controlling the total volume of the released gaseous species formed in-situ. However, in the case of n$\mathrm{C}_{10} \mathrm{H}_{21} \mathrm{O}$ group-functionalized amorphous silica, the micropore volume did not increase linearly with the $\mathrm{Si} / \mathrm{n}-\mathrm{C}_{10} \mathrm{H}_{21} \mathrm{OH}$ ratio, which is due to the remaining excess of $n-\mathrm{C}_{10} \mathrm{H}_{21} \mathrm{OH}$ as demonstrated by the FT-IR spectroscopy and TG-MS. The unreacted n$\mathrm{C}_{10} \mathrm{H}_{21} \mathrm{OH}$ as well as xylene which is physically trapped within the hybrid material, were released up to at $300^{\circ} \mathrm{C}$. The resulting micropore units formed in-situ at the initial heat treatment step are thermodynamically unstable, and collapsed during heat treatment at $600^{\circ} \mathrm{C}$. In contrast, the in-situ formation of $\mathrm{CO}_{2}$ was found to be continuous up to approximately $650^{\circ} \mathrm{C}$. Thus, among the in-situ formed small gaseous species, $\mathrm{CO}_{2}$ could act as a particularly crucial key factor for the microporosity formation process in the amorphous silica.

In this study, microporous amorphous silica materials were successfully synthesized through the polymer-derived ceramics (PDCs) route via alkoxy group-functionalized amorphous silicabased hybrids. The amount of alkoxy group was found to play an important part in controlling the volume of micropores formed in-situ. Thus, the stoichiometric reaction between the $\mathrm{Si}-\mathrm{H}$ groups in PHPS and an appropriate amount of alcohol leads to the precise control of micropore volume in the final silica material. In this respect, use of reaction catalyst such as Lewis acid would be attractive to achieve the stoichiometric reaction. It is also important to perform quantitative analysis of carbon content in the alkoxy-group-functionalized amorphous silicabased hybrids. These key aspects have been given into consideration for our ongoing studies.

\section{Summary}

In this study, PHPS was modified with $\mathrm{n}-\mathrm{C}_{5} \mathrm{H}_{11} \mathrm{OH}$ and n$\mathrm{C}_{10} \mathrm{H}_{21} \mathrm{OH}$. The chemically modified PHPSs were converted to alkoxy group-functionalized amorphous silica-based inorganicorganic hybrids under room temperature oxidation, and subsequently heat-treated at $600^{\circ} \mathrm{C}$ in air. The results can be summarized as follows.

(1) The alkoxy-group functionalized PHPSs were successfully converted into amorphous silica-based hybrids materials by exposure to vapour from aqueous ammonia at room temperature.

(2) Alkoxy-group functionalization of silica prior to the $600^{\circ} \mathrm{C}$-heat treatment in air apparently increased the micropore volume of the resulting amorphous silica, and the highest micropore volume of $0.204 \mathrm{~cm}^{3} / \mathrm{g}$ with a specific surface area of $387 \mathrm{~m}^{2} / \mathrm{g}$ was achieved for the sample derived from PHPS chemically modified with n$\mathrm{C}_{10} \mathrm{H}_{21} \mathrm{OH}$ at the $\mathrm{Si} / \mathrm{n}-\mathrm{C}_{10} \mathrm{H}_{21} \mathrm{OH}$ molar ratio of $2 / 1$.

(3) The micropores evaluated by the SF method were in the size range of 0.43 to $1.6 \mathrm{~nm}$, and the resulting micropore size distribution peaked at $0.43 \mathrm{~nm}$. The results of TGMS analysis suggested that, among the in-situ formed small gaseous species including $\mathrm{C} 3$ and $\mathrm{C} 4$ hydrocarbon unit, $\mathrm{CO}_{2}$ gas molecules, continuously released up to approximately $650^{\circ} \mathrm{C}$, mainly contributed to the formation of micropores that were detected using $\mathrm{N}_{2}$ as a probe molecule.

\section{References}

1) R. W. Rice, Am. Ceram. Soc. Bull., 62, 889-892 (1983).

2) K. J. Wynne and R. W. Rice, Annu. Rev. Mater. Sci., 14, $297-$ 334 (1984).
3) R. Riedel and W. Dressler, Ceram. Int., 22, 233-239 (1996).

4) D. Seyferth, C. Strohmann, N. R. Dando and A. Perrotta, J. Chem. Mater., 7, 2058-2066 (1995).

5) E. Kroke, Y.-L. Li, C. Konetschny, E. Lecomte, C. Fasel and R. Riedel, Mater. Sci. Eng., R, 26, 97-199 (2000).

6) O. Funayama, M. Arai, Y. Tashiro, H. Aoki, T. Suzuki, K Tamura, H. Kaya, H. Nishii and T. Isoda, J. Ceram. Soc. Japan, 98, 104-107 (1990).

7) Y. Iwamoto, K. Sato, T. Kato, T. Inada and Y. Kubo, J. Eur. Ceram. Soc., 25, 257-264 (2005).

8) T. Kubo, E. Tadaoka and H. Kozuka, J. Mater. Res., 19, 635642 (2004).

9) T. Kubo and H. Kozuka, J. Ceram. Soc. Japan, 114, 517-523 (2006).

10) K. Miyajima, T. Eda, H. Ohta, Y. Ando and Y. Iwamoto, Ceram. Trans., 213, 87-94 (2010).

11) C. Schitco, M. S. Bazarjani, R. Riedel and A. Gurlo, J. Mater Chem. A, 3, 805-818 (2015).

12) K. Kusakabe, Z. Y. Li, H. Maeda and S. Morooka, J. Membr Sci., 103, 175-180 (1995).

13) Z. Y. Li, K. Kusakabe and S. Morooka, J. Membr. Sci., 118, 159-168 (1996).

14) T. Nagano, K. Sato, T. Saito and Y. Iwamoto, J. Ceram. Soc. Japan, 114, 533-538 (2006).

15) H. Suda, H. Yamauchi, Y. Uchimaru, I. Fujiwara and K. Haraya, Desalination, 193, 252-255 (2006).

16) R. Mourhatch, T. T. Tsotsis and M. Sahimi, J. Membr. Sci., 356, 138-146 (2010).

17) A. Takeyama, M. Sugimoto and M. Yoshikawa, Mater. Trans., 52, 1276-1280 (2011).

18) K. W. Völger, R. Hauser, E. Kroke, R. Riedel, Y. H. Ikuhara and Y. Iwamoto, J. Ceram. Soc. Japan, 114, 567-570 (2006).

19) R. Hauser, S. Nahar-Borchard, R. Riedel, Y. H. Ikuhara and Y. Iwamoto, J. Ceram. Soc. Japan, 114, 524-528 (2006).

20) R. M. Prasad, Y. Iwamoto, R. Riedel and A. Gurlo, Adv. Eng. Mater., 12, 522-528 (2010).

21) M. S. Bazarjani, M. M. Müller, H.-J. Kleebe, Y. Jüttke, I. Voigt, M. B. Yazdi, L. Alff, R. Riedel and A. Gurlo, Appl. Mater. Interfaces, 6, 12270-12278 (2014).

22) G. D. Soraru, Q. Liu, L. V. Interrante and T. Apple, Chem. Mater., 10, 4047-4054 (1998).

23) Q. Liu, W. Shi, F. Babonneau and L. V. Interrante, Chem. Mater., 9, 2434-2441 (1997).

24) L. Lee and D. S. Tsai, J. Am. Ceram. Soc., 82, 2796-2800 (1999).

25) K. Miyajima, T. Eda, B. N. Nair and Y. Iwamoto, J. Membr. Sci., 421-422, 124-130 (2012).

26) M. N. M. Sokri, Y. Daiko, S. Honda and Y. Iwamoto, J. Ceram. Soc. Japan, 123, 292-297 (2015).

27) M. Weinmann, "Chapter 7 Polysilazanes", in Inorganic Materials Ed. by R. De Jaeger and M. Gleria, Nova Science Publishers Inc., NY, USA (2007) pp. 371-413.

28) Y. Iwamoto, K. Kikuta and S. Hirano, J. Mater. Res., 13, 353361 (1998).

29) D. F. Shiver and M. A. Drezdzon, "The manipulation of air sensitive compounds", 2nd Edition, John Wiley \& Sons, Inc. (1986) pp. 30-44.

30) A. Saito and H. C. Foley, AIChE J., 37, 429-436 (1991).

31) P. Barrett, L. G. Joyner and P. H. Halenda, J. Am. Chem. Soc., 73, 373-380 (1951).

32) D. Seyferth, G. Wiseman and C. Prud'homme, J. Am. Ceram. Soc., 66, C-13-C-14 (1983).

33) R. M. Silverstein, G. C. Bassler and T. C. Morrill, "Spectrometric Identification of Organic Compounds", 5th Edition, John Wiley \& Sons, Inc. (1991).

34) S. E. Stein, "Mass Spectra" in NIST Chemistry WebBook, NIST Standard Reference Database Number 69, Eds. P. J. Linstrom and W. G. Mallard, National Institute of Standards and Technology, Gaithersburg MD, 20899, http://webbook. 
nist.gov, (retrieved April 2, 2015).

35) J. M. D. Cruz, V. V. Lozovoy and M. Dantus, J. Phys. Chem. Lett. A., 109, 8447-8450 (2005).

36) A. A. Chuiko, React. Kinet. Catal. Lett., 50, 1-13 (1993).

37) E. A. Leed and C. G. Pantano, J. Non-Cryst. Solids, 325, 4860 (2003).

38) R. J. Ouellette and J. D. Rawn, "Organic Chemistry: Structure, Mechanism, and Synthesis" 1st edition, Elsevier Inc. (2014) pp. $480-482$.

39) R. M. Smith, "Understanding Mass Spectra: A Basic Approach", 2nd edition, John Wiley \& Sons, Inc. (2004) pp. 199-200.

40) R. A. W. Johnstone, "Mass Spectrometry for Organic Chem- ists" Cambridge Chemistry Texts, Cambridge University Press (1972) pp. 64-67.

41) J. T. Watson and O. D. Sparkman, "Introduction to Mass Spectrometry: Instrumentation, Applications, and Strategies for Data Interpretation", 4th edition, John. Wiley \& Sons, Inc. (2013) pp. 368-376.

42) S. T. Oyama, D. Lee, P. Hacarlioglu and R. F. Saraf, J. Membr. Sci., 244, 45-53 (2004).

43) P. Hacarlioglu, D. Lee, G. V. Gibbs and S. T. Oyama, J. Membr. Sci., 313, 277-283 (2008).

44) D. W. Breck, "Zeolite Molecular Sieves", John Wiley \& Sons, New York (1974) p. 636. 